\title{
Preparation of nanosized barium zirconate powder by thermal decomposition of urea in an aqueous solution containing barium and zirconium, and by calcination of the precipitate
}

\author{
F. Boschini*, B. Robertz, A. Rulmont, R. Cloots \\ Laboratoire de chimie inorganique structurale, Department of Chemistry, Chemistry Inst. B6, University of Liège, Sart Tilman, B-4000 Liège, Belgium
}

Received 15 September 2002; received in revised form 14 January 2003; accepted 24 January 2003

\begin{abstract}
The synthesis of barium zirconate was initiated by urea induced homogeneous precipitation followed by a "low temperature" thermal treatment. The kinetic of the reaction and the optimum urea/cation ratio have been determined by means of X-ray diffraction and Inductive Coupled Plasma analyses. It has been demonstrated that an amorphous zirconium hydrated oxide starts to precipitate followed by the precipitation of barium carbonate. A calcination at $1200{ }^{\circ} \mathrm{C}$ during $2 \mathrm{~h}$ gives rise to the formation of a pure barium zirconate phase. Microstructural characterisations have been performed in order to evaluate the sintering behaviour. Dilatometric measurements, coupled with scanning electron microscopy analyses clearly indicate that barium carbonate decomposition process leads to the formation of internal porosity which severely limits the density of the material, even if a sintering was performed at $1500{ }^{\circ} \mathrm{C}$. A careful control of the heating profile seems to be necessary in order to produce dense materials.

(C) 2003 Elsevier Ltd. All rights reserved.
\end{abstract}

Keywords: $\mathrm{BaZrO}_{3}$; Calcination; Powders-chemical preparation; Sintering

\section{Introduction}

Barium zirconate is a very promising refractory structural material with a very high melting point $\left(2600{ }^{\circ} \mathrm{C}\right)$ and a low chemical reactivity towards corrosive compounds like high temperature superconductors. Erb et al. showed that high density barium zirconate could be used as a substrate in the synthesis of high-Tc superconductors because it does not react with the liquid phases produced at high temperature during the process. ${ }^{1}$

A simple method to synthetise barium zirconate can be the traditional solid state reaction route in which an appropriate amount of zirconia and barium carbonate are mixed together, ball milled to both enhance the homogeneity and reduce the particle size, before performing the heat treatment. ${ }^{2}$ However, for such refractory materials, it is necessary to make several cycles of grinding/firing during a rather long heating time in order to complete the reaction. Moreover, powders

\footnotetext{
* Corresponding author.

E-mail address: frederic.boschini@ulg.ac.be (F. Boschini).
}

produced by such a process still keep several drawbacks like a lack of reproducibility, a large particle size (10 $\mu \mathrm{m})$ and size distribution, a high degree of aggregation and sometimes inhomogeneities in the chemical composition. To avoid these effects, different synthesis methods have been developed like the citrate route, the oxalate route ${ }^{3,4}$ or the metal -chelate sol-gel route using ethylene glycol as complexing agent. ${ }^{5,6}$ In all these methods, the powder is obtained after a low temperature calcination $\left(<1000{ }^{\circ} \mathrm{C}\right)$ of the precursor. Recently, barium zirconate has been produced by a co-precipitation in presence of ammonia and ammonium carbonate in order to precipitate quantitatively barium and to obtain after calcination a stoechiometric barium zirconate product. ${ }^{7}$ To own knowledge, urea has not yet been reported as a precipitation agent for the production of barium zirconate.

The first objective of this work is to produce fine powders of stoechiometric $\mathrm{BaZrO}_{3}$ by homogeneous precipitation using the urea decomposition in solution without addition of any other salts to ensure a quantitative precipitation of barium ions. The second main objective is to study the behaviour of this powder at 
high temperature to know its ability to produce highly dense ceramic parts. We have studied the effect of different synthesis parameters on the powder characteristics. Thermoanalytical studies, induced coupled plasma (ICP) analysis to determine the ratio $\mathrm{Ba} / \mathrm{Zr}$ in the powder, X-ray diffraction (XRD) measurements to follow the evolution of barium zirconate phase synthesis and microscopic studies were performed on the precursors and on the final powder. The results are presented hereafter.

\section{Experimental procedure}

\subsection{Precipitation method}

Commercial products were used as the precursors. Barium chloride dihydrate $99 \%$ pure from Vel was chosen as the barium source. The zirconium source was $98 \%$ pure of $\mathrm{ZrOCl}_{2}$, from Avocado, and urea was $99 \%$ pure from Vel.

We first prepare a clear aqueous solution by dissolving appropriate quantities of $\mathrm{BaCl}_{2} \cdot 2 \mathrm{H}_{2} \mathrm{O}$ and $\mathrm{ZrOCl}_{2} .8 \mathrm{H}_{2} \mathrm{O}(\mathrm{pH}=0.5)$. The total concentration of cations in the mixed solution is kept at $0.5 \mathrm{~mol} / \mathrm{l}$ with a molar ratio $\mathrm{Ba} / \mathrm{Zr}$ equal to 1.00 . Of this solution $(50 \mathrm{ml})$ are added to a solution of $25 \mathrm{ml}$ of water containing 30 $\mathrm{g}$ of urea. The solution is then heated to $90{ }^{\circ} \mathrm{C}$ during 24 $\mathrm{h}$ under stirring to allow the urea decomposition. A white precipitate progressively appears. The white solid phase in suspension is then separated from the solution by centrifugation at $4000 \mathrm{rpm}$, washed twice with deionised water and dried at $100{ }^{\circ} \mathrm{C}$ during $12 \mathrm{~h}$ before being heat-treated at $1200{ }^{\circ} \mathrm{C}$ for $2 \mathrm{~h}$.

In order to find the optimum conditions for the preparation of the barium zirconate powder, we investigated the role of both the molar ratios urea/cations (from 5 to 30) and the effect of the reaction time on formation of $\mathrm{BaZrO}_{3}$ while keeping the other experimental parameters unchanged.

\subsection{Powder characterisation}

The crystallographic identification of the as-produced phases was performed by XRD with a Siemens D5000 diffractometer (Ni filtered $\mathrm{Cu} K_{\alpha}$ radiation). The thermal treatment of the powders was performed in air with a heating rate of $3{ }^{\circ} \mathrm{C} \mathrm{min}^{-1}$. Pre-calcined powders were pressed in a pellet shape. A sintering of the pellets was performed at $1200,1300,1400$ and $1500{ }^{\circ} \mathrm{C}$ respectively. The particle size, the morphology of the powder and the microstructure of the sintered pellets were studied by scanning electron microscopy (SEM) (Hitachi S-2500).

Fourier transformation infra red spectrometry (Perkin-Elmer FT-IR) was used to identify the IR active functional groups using the $\mathrm{KBr}$ pellet technique. The thermal analysis of the powders was performed in a flowing air atmosphere by using a DSC/DTA/TG apparatus (STA 449C, Netzsch) with a heating rate of $10{ }^{\circ} \mathrm{C} \mathrm{min}-1$. The barium and the zirconium contents of the samples were determined by inductively coupled plasma spectroscopy (ICP): $0.1 \mathrm{~g}$ of dry powder was dissolved in $3 \mathrm{ml}$ of hot hydrochloric acid and then diluted with cold de-ionized water up to a volume of 11 .

Densification was studied on a Setaram dilatometer. The dilatometric curves were registered on rods which were isostatically pressed at $200 \mathrm{MPa}$. Density and open porosity measurements were performed by the Archimedes technique in water on ceramics pellets obtained by pre-pressing the powder uniaxially at $625 \mathrm{MPa}$. The relative density was calculated based on a theoretical density value equal to $6.23 \mathrm{~g} \mathrm{~cm}^{-3}$ for $\mathrm{BaZrO}_{3}$.

\section{Results and discussion}

A precipitate is formed in the solution due to an increase of the $\mathrm{pH}$ induced by the decomposition of urea at $90{ }^{\circ} \mathrm{C}$, according to the following reaction:

$$
\left(\mathrm{H}_{2} \mathrm{~N}\right)_{2} \mathrm{CO}+3 \mathrm{H}_{2} \mathrm{O} \stackrel{\Delta}{\rightarrow} \mathrm{CO}_{2}+2 \mathrm{NH}_{3}+2 \mathrm{H}_{2} \mathrm{O}
$$

The decomposition of urea gives rise to a controlled release of ammonia and carbon dioxide into the solution. $\mathrm{OH}^{-}$and $\mathrm{CO}_{3}^{2-}$ ions induce the precipitation of metal hydroxides and hydroxycarbonates ${ }^{8}$ which are the precursors for the perovskite compounds.

The precipitation reaction occurs in two steps. The first step corresponds to the precipitation of the zirconium hydroxide at $\mathrm{pH} 2$, which rapidly forms a gel after $\frac{1}{2} \mathrm{~h}$ at $90{ }^{\circ} \mathrm{C}$ due to the formation of hydrated $-\mathrm{Zr}-\mathrm{O}-$ $\mathrm{Zr}-$ polymeric chains. The gel structure is amorphous (Fig. $1 \mathrm{~A}$ ) but we can have some insight on its composition by performing a calcination at $1000{ }^{\circ} \mathrm{C}$ for $2 \mathrm{~h}$. The resulting XRD pattern of this calcined gel is given in Fig. 1B. The solid obtained is a mixture of zirconia and barium zirconate phases. This means that after $\frac{1}{2} \mathrm{~h}$ at $90{ }^{\circ} \mathrm{C}$, the barium carbonate precipitation seems to be not quantitative. ICP analyses performed on the calcined gel show in fact that the $\mathrm{Ba} / \mathrm{Zr}$ ratio is close to 0.1 .

The second step corresponds to the barium carbonate precipitation. Barium carbonate can be detected on the $\mathrm{X}$-ray diffraction pattern performed on the non-calcined solid phase separated from the solution after a $24 \mathrm{~h}$ reaction time at $95{ }^{\circ} \mathrm{C}$ (Fig. 1C). Fig. 2 shows the SEM photomicrograph of this non calcined solid phase obtained after separation from the solution.

Notice in Fig. $1 \mathrm{C}$ the formation of $\mathrm{BaCO}_{3}$ after a $24 \mathrm{~h}$ reaction time at $95{ }^{\circ} \mathrm{C}$, and in Fig. $1 \mathrm{~A}$ the amorphous structure of the non calcined gel obtained after a reaction time of $30 \mathrm{~min}$ at $90{ }^{\circ} \mathrm{C}$. In Fig. $1 \mathrm{~B}$ the XRD pattern of the calcined gel is presented $\left(2 \mathrm{~h}\right.$ at $\left.1000^{\circ} \mathrm{C}\right)$. 


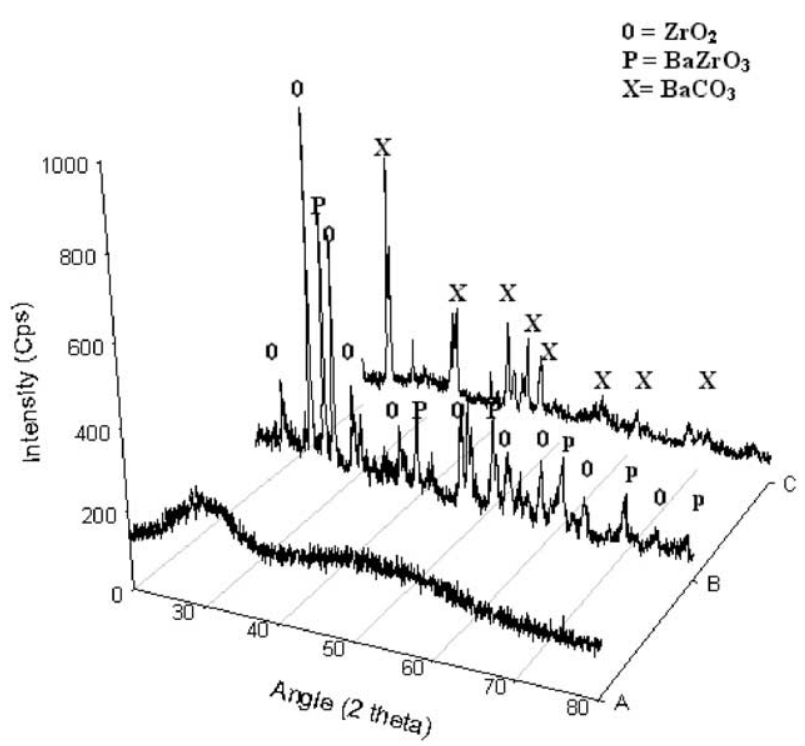

Fig. 1. Evolution of the X-ray diffraction pattern as a function of time performed on the solid phase separated from the solution.

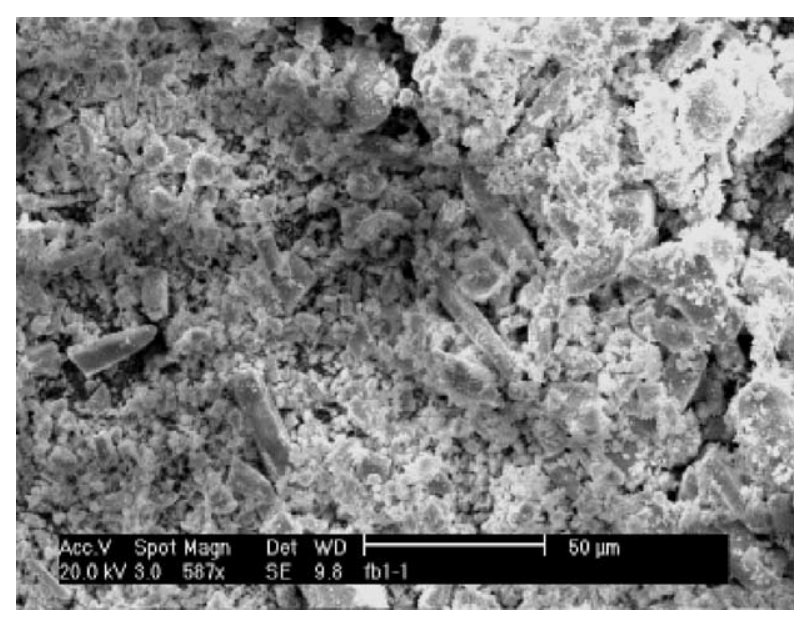

Fig. 2. SEM photomicrograph of the gel obtained after a reaction time of $24 \mathrm{~h}$ at $95^{\circ} \mathrm{C}$ (magnification rate: $587 \mathrm{x}$ ).

\subsection{ICP-analysis}

In order to evaluate the optimum urea/cations molar ratio, we decided to isolate the precipitates from the solution, obtained by modifying the initial urea/cations molar ratio for a $24 \mathrm{~h}$ reaction time, at $90{ }^{\circ} \mathrm{C}$. ICP analysis was performed on each gel obtained at $90{ }^{\circ} \mathrm{C}$ after a $24 \mathrm{~h}$ reaction time for different urea/cations molar ratio. The results are presented in Fig. 3. As deduced from Fig. 3, quantitative precipitation only occurs when the molar urea/cation ratio is greater than 20 .

It is important to mention that the kinetic of the solid phase formation is relatively slow as deduced from Fig. 4.

ICP analyses were performed as a function of time on equivalent aliquots of the precipitates formed at $90{ }^{\circ} \mathrm{C}$. The initial urea/cations molar ratio was fixed at 30 . The

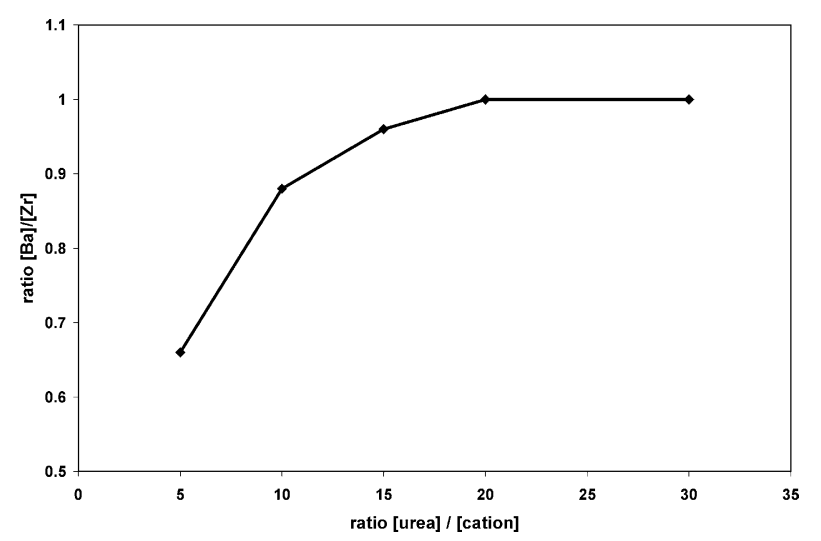

Fig. 3. Value of the $\mathrm{Ba} / \mathrm{Zr}$ molar ratio as a function of the urea/ cations ratio for the gel obtained at $90{ }^{\circ} \mathrm{C}$ after a $24 \mathrm{~h}$ reaction time.

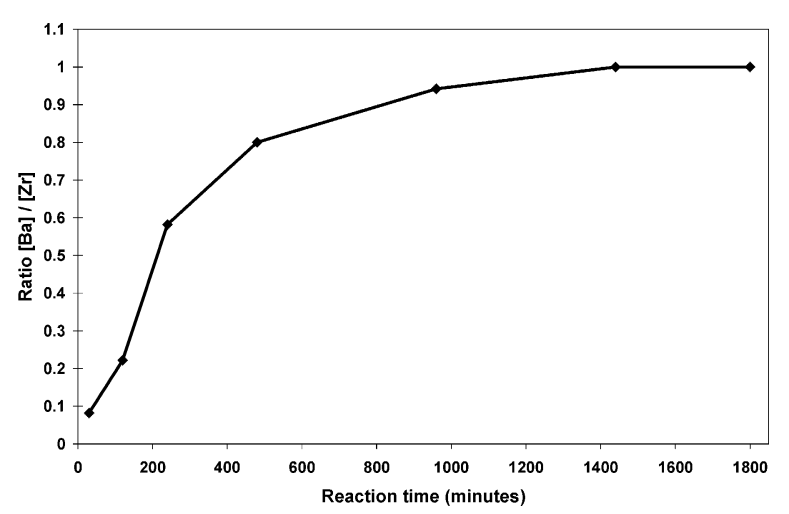

Fig. 4. Value of the $\mathrm{Ba} / \mathrm{Zr}$ molar ratio as a function of the reaction time for the gel obtained at $90{ }^{\circ} \mathrm{C}$.

precipitation is quantitative only after a $24 \mathrm{~h}$ reaction time. The slow kinetic process of urea decomposition and subsequent precipitation of the precursors ensure the formation of homogeneous fine particles.

\subsection{XRD analysis}

In order to determine the optimum heat treatment which has to be performed on the solid precursor obtained by precipitation, we decided to follow the reaction course by heating the solid mixture at increasing temperatures, and measuring the corresponding X-ray diffraction pattern at room temperature. The results are gathered in Fig. 5.

Below $600{ }^{\circ} \mathrm{C}$, we only observed the diffraction peaks corresponding to $\mathrm{BaCO}_{3}$. This means that the amorphous hydrated zirconia phase does not crystallize below $600{ }^{\circ} \mathrm{C}$. A new crystalline phase appeared only at $700{ }^{\circ} \mathrm{C}$ but it is difficult to identify this phase clearly because the most important peak of $\mathrm{ZrO}_{2}\left(2 \theta=30.27^{\circ}\right)$ and $\mathrm{BaZrO}_{3}\left(2 \theta=30.17^{\circ}\right)$ are lying almost at the same position even if small intensity reflection peaks at $50.37^{\circ}$ and $60.20^{\circ} 2 \theta$ could however be assigned to the $\mathrm{ZrO}_{2}$ tetragonal phase. Crystalline $\mathrm{BaZrO}_{3}$ phase is clearly present in the X-ray diffraction pattern at $800{ }^{\circ} \mathrm{C}$ (see 


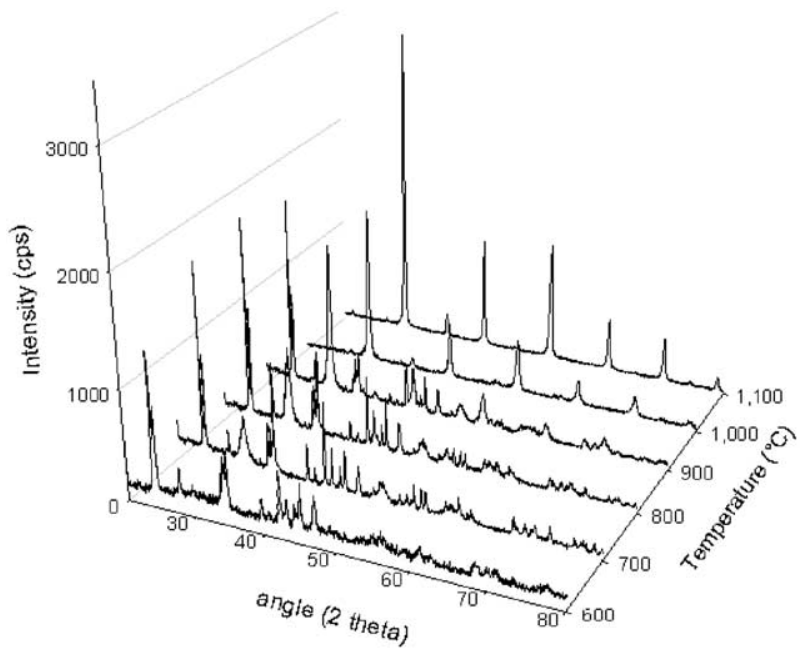

Fig. 5. Evolution of the reacting mixture calcined in between 600 and $1100{ }^{\circ} \mathrm{C}$ (measurements performed at room temperature).

Fig. 5). We can conclude that the $\mathrm{BaZrO}_{3}$ starts to form in between 700 and $800{ }^{\circ} \mathrm{C}$, and by increasing temperature further the intensity of $\mathrm{BaZrO}_{3}$ diffraction peaks increases while the intensity of the diffraction peaks corresponding to the $\mathrm{BaCO}_{3}$ phase gradually decreases. At $1100{ }^{\circ} \mathrm{C}$, the $\mathrm{BaCO}_{3}$ phase has totally disappeared and a pure $\mathrm{BaZrO}_{3}$ phase is thus obtained.

\subsection{SEM analysis}

Fig. 6a and b, shows SEM photomicrographs of pure barium zirconate powders obtained after a calcination at $1200{ }^{\circ} \mathrm{C}$ for $2 \mathrm{~h}$. The particles are spherical and their size lies in the range of $50-120 \mathrm{~nm}$ with some bigger aggregates characterized by a diameter close to $300 \mathrm{~nm}$. A lot of neck-formation between particles can be seen in Fig. 6b. Moreover, particle size distribution of the powder calcined at $1200{ }^{\circ} \mathrm{C}$ was measured by laser diffusion. The granulometric curve (see Fig. 7) shows a large size distribution which indicates a high degree of agglomeration. This size distribution lies between 0.2 and $25 \mu \mathrm{m}$. The median in volume distribution is 2.3 $\mu \mathrm{m}$.

\subsection{FTIR analysis}

Fig. 8 shows the FTIR spectra of respectively the powder calcined at $1200^{\circ} \mathrm{C}$ for $2 \mathrm{~h}$ and the gel obtained at $90{ }^{\circ} \mathrm{C}$ by centrifugation from the solution after a $24 \mathrm{~h}$ reaction time. Pure barium carbonate IR spectrum is given for comparison.

A broad bump appears at around $3450 \mathrm{~cm}^{-1}$ for the gel corresponding to the presence of water and hydroxyl groups adsorbed onto the gel particles. The small peaks around $2350 \mathrm{~cm}^{-1}$ observed in each sample have been attributed to atmospheric $\mathrm{CO}_{2}$. A large vibration band at $1450 \mathrm{~cm}^{-1}$ and two other sharp vibration bands at 850 and $690 \mathrm{~cm}^{-1}$ respectively have been observed in the gel and have been attributed to the existence of $\mathrm{CO}_{3}^{2-}$ groups by comparison with pure $\mathrm{BaCO}_{3}$.

The large vibration band observed around $530 \mathrm{~cm}^{-1}$ in the calcined powder is due to $\mathrm{Zr}-\mathrm{O}$ vibration in the perovskite structure.

\subsection{Thermoanalytical studies}

The TG-DSC curve (see Fig. 9) of the dried precipitate obtained at $90{ }^{\circ} \mathrm{C}$, after a $24 \mathrm{~h}$ reaction time shows a first endotherm at $100{ }^{\circ} \mathrm{C}$ and a second around $220{ }^{\circ} \mathrm{C}$. These two endotherms can be assigned to the water loss from the zirconia gel. The exotherm at $720{ }^{\circ} \mathrm{C}$ is rather broad and corresponds to the crystallisation of both $\mathrm{ZrO}_{2}$ or $\mathrm{BaZrO}_{3}$ phases. ${ }^{9}$ The endotherm at $809^{\circ} \mathrm{C}$ is related to the $\gamma$ to $\beta$ polymorphic phase transformation of $\mathrm{BaCO}_{3}$ which takes place theoretically at $805^{\circ} \mathrm{C}$. The other $\mathrm{BaCO}_{3}$ phase transformation at $982{ }^{\circ} \mathrm{C}$ is not observed. The last endotherm at $1137{ }^{\circ} \mathrm{C}$ corresponds to the decomposition of $\mathrm{BaCO}_{3}$, which produces a big mass loss in the TG curve. No important mass loss was
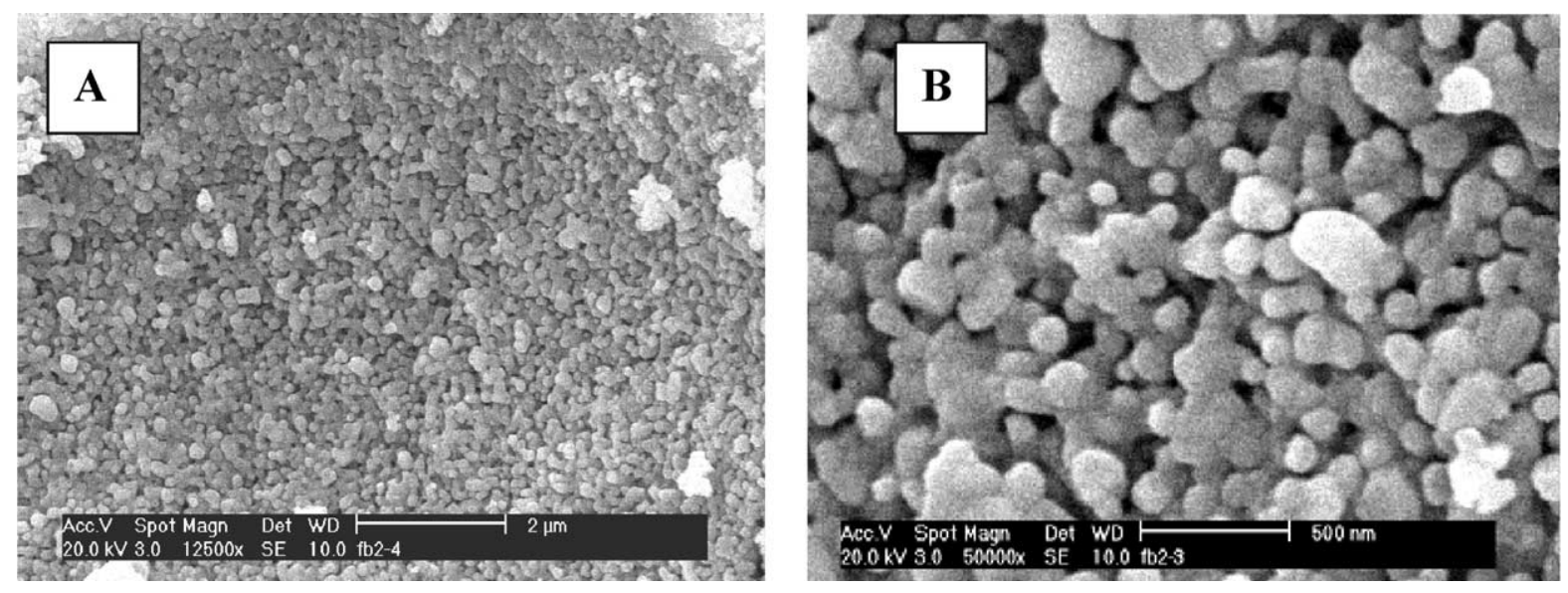

Fig. 6. SEM photomicrographs of calcined $\mathrm{BaZrO}_{3}$ powder at $1200{ }^{\circ} \mathrm{C}$ for $2 \mathrm{~h}$ (A) $12,500 \times$ and (B) $50,000 \times$. 


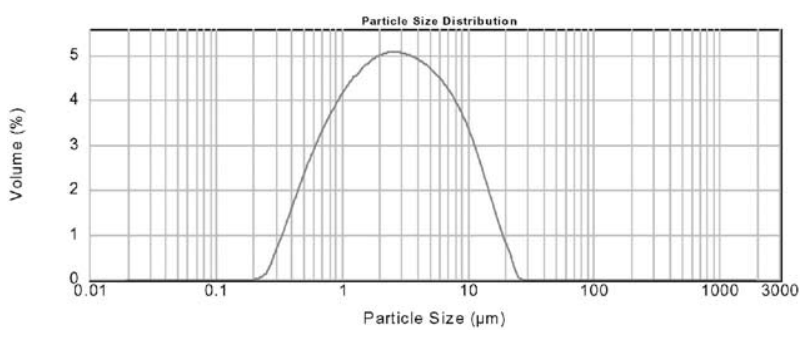

Fig. 7. Particle size distribution of calcined $\mathrm{BaZrO}_{3}$ powder at $1200^{\circ} \mathrm{C}$ for $2 \mathrm{~h}$.

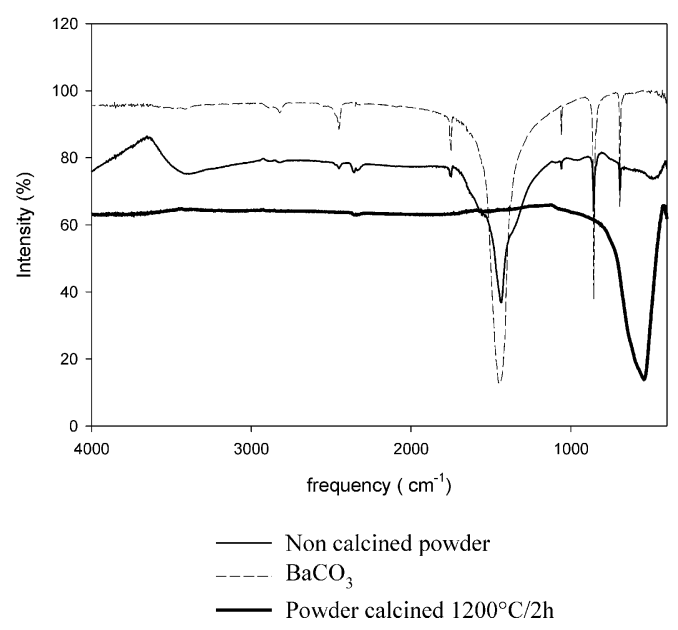

Fig. 8. FTIR spectra of $(-)$ the powder calcined at $120{ }^{\circ} \mathrm{C}$ for $2 \mathrm{~h}$, (-) the gel obtained at $90^{\circ} \mathrm{C}$ after a $24 \mathrm{~h}$ reaction time, and, (-- - ) pure $\mathrm{BaCO}_{3}$.

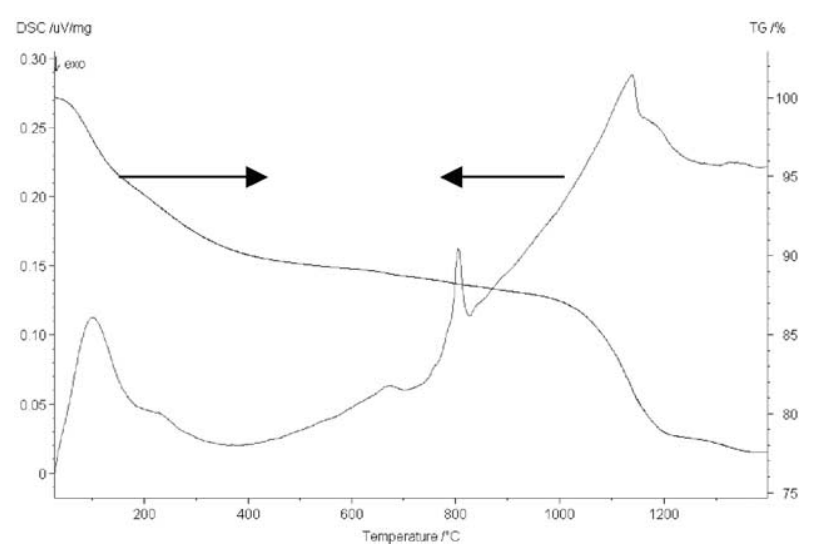

Fig. 9. TG-DSC curves of the dried powder obtained by precipitation at $90{ }^{\circ} \mathrm{C}$ after a $2 \mathrm{~h}$ reaction time.

detected at higher temperature. Notice however that a slight mass loss has been detected around $1350^{\circ} \mathrm{C}$ which can be attributed to a residual barium carbonate decomposition. These results do not totally agree with the previous X-ray diffraction investigations: (1) the $\mathrm{BaCO}_{3}$ polymorph transformation could not be seen between $800{ }^{\circ} \mathrm{C}$ and $900{ }^{\circ} \mathrm{C}$, which is expected for a reversible process, (2) the $\mathrm{BaCO}_{3}$ phase completely disappeared below $1100{ }^{\circ} \mathrm{C}$ as the reaction is completed at $1000{ }^{\circ} \mathrm{C}$ (see Fig. 5). Informations obtained by this two techniques are different because the heating rate was very different and the reaction kinetic is supposed to be rather slow.

\subsection{Calcination and sintering}

The shrinkage behaviour has been studied by means of high temperature dilatometry. Fig. 10 shows two distinct behaviours, in the dilatometric curve, below $1250{ }^{\circ} \mathrm{C}$ and above $1250{ }^{\circ} \mathrm{C}$, marked by the onset of shrinkage at this temperature. A small increase in shrinkage is observed in the range $200-1000{ }^{\circ} \mathrm{C}$, which is probably due to the thermal expansion of the material.

Table 1 shows density and open porosity measurements performed on samples obtained after sintering at different temperatures.

In order to evaluate the influence of the sintering temperature on the densification process, powders obtained by the urea homogeneous precipitation method were first calcined at $1200^{\circ} \mathrm{C}$ for $2 \mathrm{~h}$ and pelletised. These pellets were then sintered at different temperatures. Fig. 11 shows the evolution of the microstructure of the material analysed by means of scanning electron microscopy performed on the pellet surface of the different samples.

Open porosity highly decreases with the increase of the sintering temperature (see also Table 1). This open porosity reduction can be observed with more details in Fig. 11. Densification is maximum around $1300{ }^{\circ} \mathrm{C}$. $\mathrm{BaZrO}_{3}$ sintered at 1400 and $1500{ }^{\circ} \mathrm{C}$ shows a strong enlargement in grain size (Fig. 11c and d). The average grain size is in the range of $150 \mathrm{~nm}$ around $1300{ }^{\circ} \mathrm{C}, 400$ $\mathrm{nm}$ around $1400{ }^{\circ} \mathrm{C}$ and $3 \mu \mathrm{m}$ around $1500{ }^{\circ} \mathrm{C}$. Thus, the enlargement in grain size is believed to have contributed to the decrease in sintered density, as shown in Table 1 .

But an important effect to explain the decrease of the density is also the probably residual barium carbonate decomposition around $1350{ }^{\circ} \mathrm{C}$ as shown on the ATGDSC curve. The barium carbonate decomposition

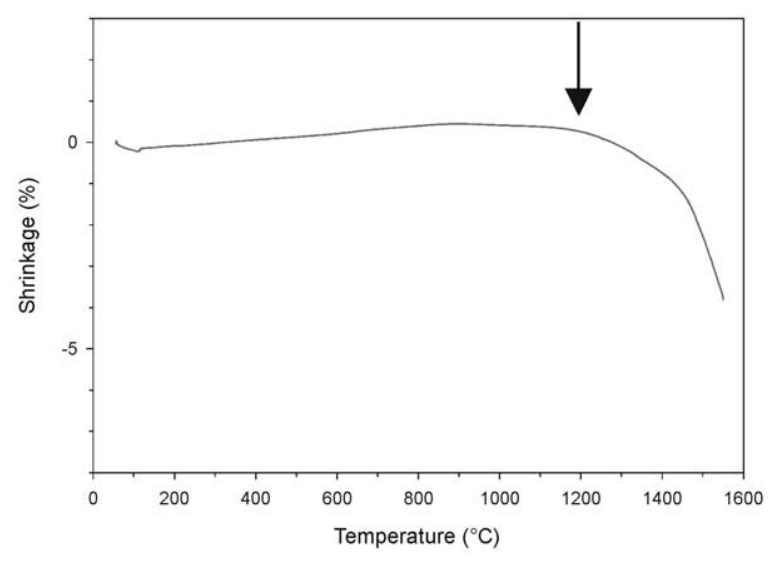

Fig. 10. Dilatometric curve. 

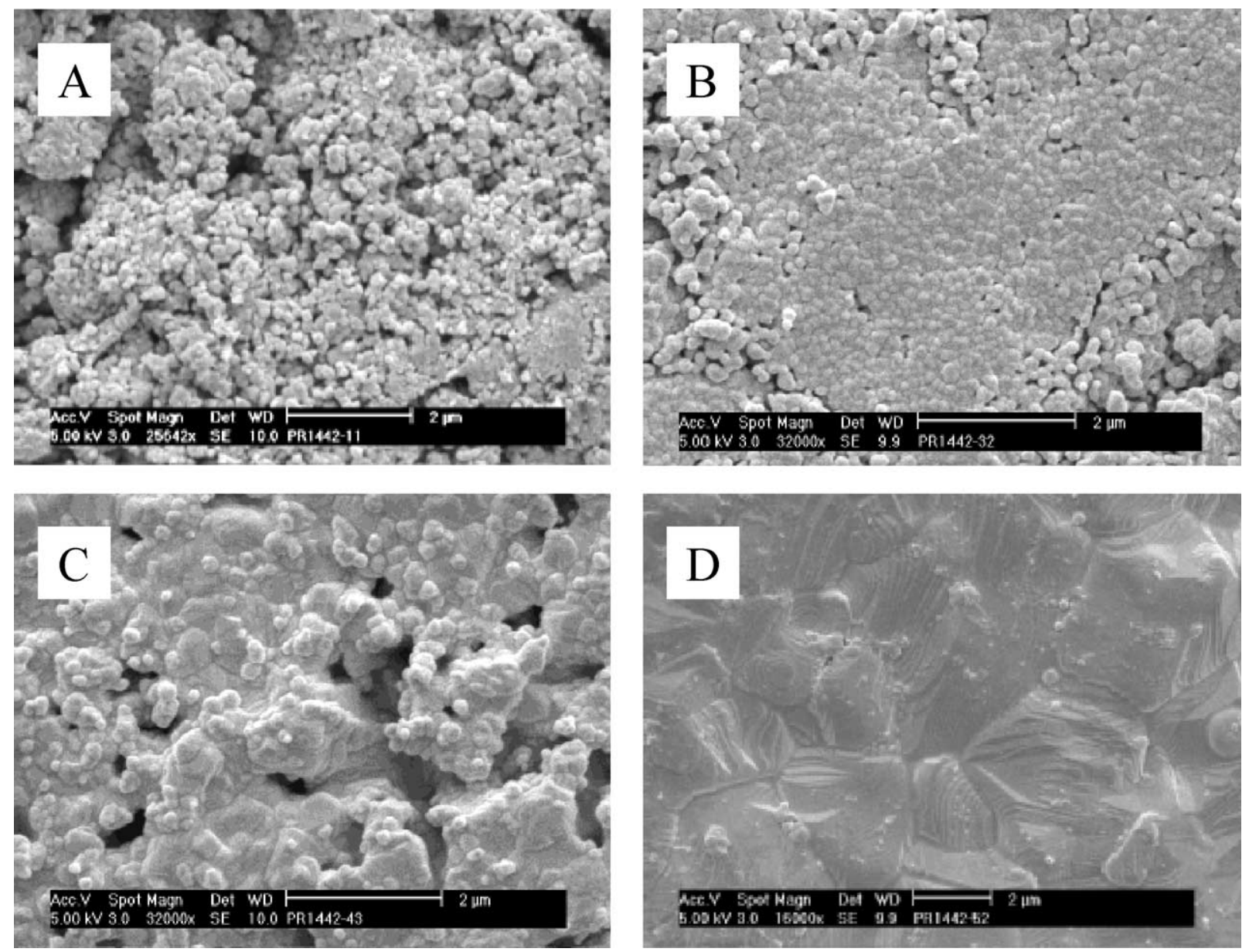

Fig. 11. SEM photomicrographs of the pellets surface sintered at $1200^{\circ} \mathrm{C}(\mathrm{A}), 1300{ }^{\circ} \mathrm{C}(\mathrm{B}), 1400{ }^{\circ} \mathrm{C}(\mathrm{C})$ and $1500{ }^{\circ} \mathrm{C}(\mathrm{D})$, for $2 \mathrm{~h}$ with a heating rate of $3{ }^{\circ} \mathrm{C} / \mathrm{min}$.

releases carbon dioxide which forms internal porosity. Porosity cannot be eliminated from the material even by increasing the sintering time (see photomicrograph of Fig. 13).

Fig. 12 shows SEM photomicrographs performed on polished cross-section of $\mathrm{BaZrO}_{3}$ pellets sintered at $1200{ }^{\circ} \mathrm{C}(\mathrm{a}), 1300{ }^{\circ} \mathrm{C}(\mathrm{b}), 1400{ }^{\circ} \mathrm{C}$ (c), and $1500{ }^{\circ} \mathrm{C}$ (d) for $2 \mathrm{~h}$ with a heating rate of $3{ }^{\circ} \mathrm{C} / \mathrm{min}$. Densification seems to begin at $1300{ }^{\circ} \mathrm{C}$ but porosity inside the pellet at this temperature is still very high. At $1400{ }^{\circ} \mathrm{C}$, densification seems better than at $1300{ }^{\circ} \mathrm{C}$ and the inside porosity decreases, but some porosity is trapped inside the pellet (see Fig. 13). At $1500{ }^{\circ} \mathrm{C}$ (D), pores increase greatly and relative density decreases as it is shown in Table 1.

\section{Conclusion}

This study has shown that barium zirconate can be prepared by urea induced homogeneous precipitation followed by a low temperature thermal treatment. The reaction time and the urea/cation ratio have to be carefully controlled in order to obtain a powder with a $\mathrm{Ba} / \mathrm{Zr}$ ratio equal to 1 . Zirconium hydrated oxide starts to precipitate rapidly after a $20 \mathrm{~min}$ reaction time while the formation of barium carbonate is not so fast. For an urea/cation ratio equal to 30 , the time required to obtain a quantitative precipitation of the barium is around $24 \mathrm{~h}$. We showed that this technique is very simple to use, and can give very small particles with typical size around $90 \mathrm{~nm}$, and thus with a high agglomeration state after the calcination step at $1200^{\circ} \mathrm{C}$. In comparison with the solid state reaction, this technique does not require long reaction time at high

Table 1

Shows density and open porosity measurements performed on samples obtained after sintering at different temperatures.

\begin{tabular}{lll}
\hline Sintering temperature $\left({ }^{\circ} \mathrm{C}\right)$ & \multicolumn{2}{l}{ Archimedes measurements } \\
\cline { 2 - 3 } & Density $(\%)$ & Open porosity $(\%)$ \\
\hline 1200 & 96.6 & 26.4 \\
1300 & 97.5 & 19.6 \\
1400 & 94.7 & 11.2 \\
1500 & 93.3 & 3.6 \\
\hline
\end{tabular}



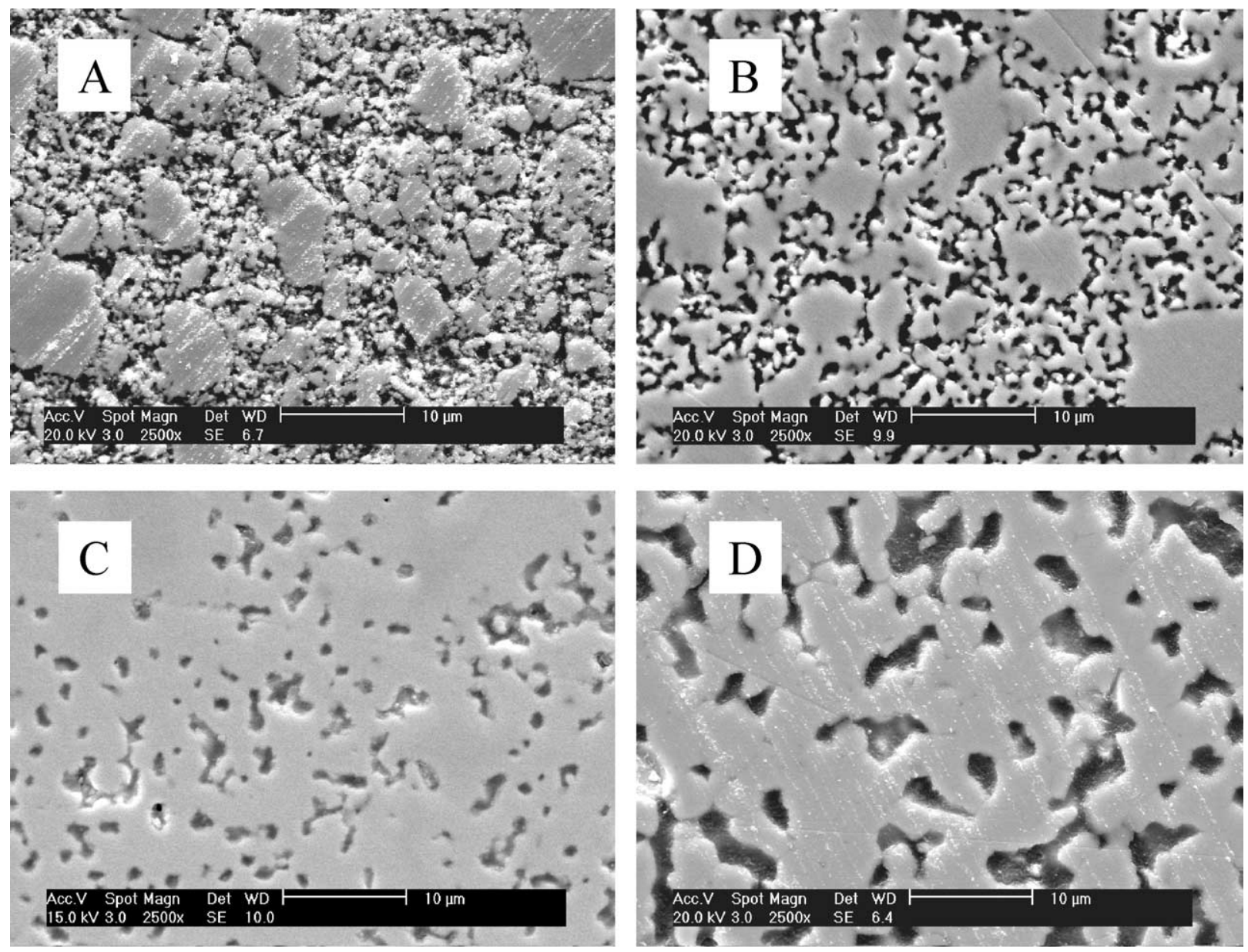

Fig. 12. SEM photomicrographs of polished cross section of $\mathrm{BaZrO}_{3}$ pellets sintered at $1200{ }^{\circ} \mathrm{C}(\mathrm{A}), 1300{ }^{\circ} \mathrm{C}(\mathrm{B}), 1400{ }^{\circ} \mathrm{C}(\mathrm{C})$, and $1500{ }^{\circ} \mathrm{C}(\mathrm{D})$ for $2 \mathrm{~h}$ with a heating rate of $3{ }^{\circ} \mathrm{C} / \mathrm{min}$.

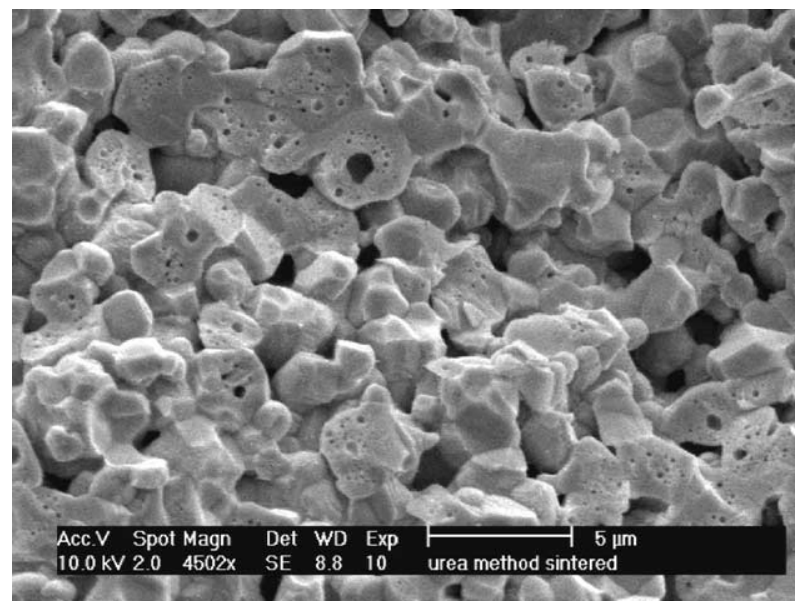

Fig. 13. SEM photomicrograph of a $\mathrm{BaZrO}_{3}$ pellet sintered at $1450{ }^{\circ} \mathrm{C}$ for $12 \mathrm{~h}$. Notice the trapped porosity inside the grains.

temperature to obtain the product. Only $2 \mathrm{~h}$ are necessary to obtain pure $\mathrm{BaZrO}_{3} .93 .3 \%$ of the theoretical density is obtained after a sintering at $1500{ }^{\circ} \mathrm{C}$ during two hours. Progress have to be done in order to inverse the density of the end-product. A prolonged heating time at $1300{ }^{\circ} \mathrm{C}$ can be efficient for porosity release. The problem of trapped porosity is effectively crucial in order to optimise the density of the end-product. The urea decomposition technique could also be used to produce doped powders with variable $\mathrm{Ba} / \mathrm{Zr}$ ratios.

\section{Acknowledgements}

The region Wallonne is gratefully acknowledged for financial support. We would like to thank the Laboratoire de Chimie Physique Appliquée (University of Liège-Professor J.P. Pirard) for giving access to the dilatometric measurement facilities.

\section{References}

1. Erb, A., Walker, E. and Flukiger, R.. Physica C, 1995, 245-251.

2. Von Watenburg, H. and Werth, H., Z. anorg. Chem., 1930, 190, 178.

3. Potdar, H. S., Deshpande, S. B., Godboole, P. D. and Date, S. K., J. Mater. Res., 1993, 8(5), 948-950. 
4. Gangadevi, T., Subba Rao, M. and Narayanan Kutty, T. R., J. Thermal. Anal, 1980, 19, 312-332.

5. Lee, S. J., Biegalski, M. D. and Kriven, W. M., J. Mater. Res., 1999, 14(7), 3001.

6. Veith, M., Mathur, S., Lecerf, N., Huch, V. and Decker, T., J. Sol-gel and Technol, 2000, 15, 145-158.
7. Brzezinska-Miecznik, J., Haberko, K. and Bucko, M. M., Mater. Lett., 2002, 56(3), 273-278.

8. Cornilsen, B. C. and Reed, J. S., Am. Ceram. Soc. Bull., 1979, 58, 1199-2000.

9. Limar, T. F. and Savos'Kina Russ, A. L., J. Inorg. Chem., 1970, 15(10), 1360-1362. 